\title{
Structural and Elastic Studies of Strontium Doped Manganese Borate Glasses
}

\author{
*P.Vasantharani ${ }^{1}, \mathrm{~S}$. Neelayathashi alias Vichitra ${ }^{2}$ \\ ${ }^{1}$ Department of Physics, Annamalai University, Annamalainagar - 608 002, Tamil Nadu, India.) \\ ${ }_{2}^{2}$ (Department of Physics, Annamalai University, Annamalainagar, Tamil Nadu, India.)
}

\begin{abstract}
Ternary Strontium Borate glasses were prepared using the conventional melt- quenching method. Longitudinal and shear velocities were measured at $4 \mathrm{MHz}$ at room temperature by Pulse Echo technique. Density is measured using the Archimedes principle. Elastic properties, Debye Temperature and micro hardness have been investigated using the measured velocities and densities. Results indicate that these parameters increase as the composition of $\mathrm{SrO}$ increases in the manganese borate glasses.
\end{abstract}

Keywords: Archimedes principle, Elastic moduli, Ultrasonic velocities

\section{Introduction}

Borate glasses are one of the important amorphous materials which offer varying physical and chemical properties with changes in chemical composition and thus find wide applications. Boron possess the ability to change the coordination with oxygen between three and four and hence form variable structural units in the glass network and such behavior is quite different than that of silicon and phosphorous which form only tetrahedral coordinate units with oxygen [1].

Borate glass chemistry can be influenced by the addition of different alkali and alkaline earth ions allowing for tunable solubility and bioactivity and used for different applications namely radiation dosimetry, solar energy convertors, vacuum ultraviolet optics and a number of electronic devices applications. The addition of transition and alkaline metal ions leads to interesting specific changes in the physical properties of the glasses $[2,3]$. Glasses containing transition metals have been drawing a lot of attention as they are widely used as memory and photo conducting devices [4], cathode materials in batteries [5], magnetic materials [6] etc.

Manganese borate glasses are versatile because of its chemical properties like large variety of oxidation states $[7,8,9,10,11]$. Manganese exists in different valence states with different coordination in glass matrices and the study of which with the existence of different valence states in the glass matrix depend upon the qualitative properties of modifiers, glass formers, size of the ions in the glass structure, their field strength and mobility of the modifier cation etc. [12]. It is one of the common impurities used as coloring, discoloring agent. Manganese ions have been used as paramagnetic probes for exploring the structure and properties of vitreous systems.

The addition of alkaline earth metals brings about the desirable changes in the borate glass network and strontium acts as a good modifier [13]. Strength of glass samples can be considerably improved by the doping of suitable proportion of $\mathrm{SrO}$ (14). Strontium is a therapeutic ion of particular interest in the field of bone regeneration. They have been shown to effect bone cell metabolism of both osteoblasts and osteoclasts to elicit an increase in bone mineralization [15]. SrO containing glasses and their corresponding glass ceramics can be applied as gamma ray shielding candidate [16].

Among the various experimental methods available for studying the structure - property relations, elastic properties of solid materials are of considerable significance because their measurements yield information concerning the forces between the atoms or ions. This is fundamentally important in interpreting and understanding the nature of bonding in the solid materials. Therefore the choice of the most appropriate material for particular application requires knowledge of its mechanical properties. Hence elastic properties are suitable for describing the glass structure as a function of composition [17].

Even though a lot of studies is available to explore the elastic properties of borate glasses doped with alkali, not much study are done on alkaline doped glasses. Hence an attempt is made to study the elastic properties of strontium doped manganese borate glasses.

\section{Experimental Details}

By conventional melt quenching technique, a series of oxide borate glasses of $\mathrm{xSrO}-(40-\mathrm{x}) \mathrm{MnO}_{2}-$ $60 \mathrm{~B}_{2} \mathrm{O}_{3}(\mathrm{SMB}$ ) (where $\mathrm{x}=2,4,6,8,10 \mathrm{~mol} \%$ ) were prepared. The details of composition are given in Table 1 . The required amount (approximately $15 \mathrm{~g}$ ) in mol\% of different chemicals in powder form was weighed using a single pan balance. The starting materials are thoroughly powdered, mixed and melted in a porcelain crucible at $1100^{\circ} \mathbf{C}$ for two hours in a thermal cyclic furnace until a bubble free transparent solution is formed. The 
resultant bubble free melt is then poured into a brass mould and subsequently annealed at $350^{\circ} \mathbf{C}$ for two hours to avoid the mechanical strain developed during the quenching process. The prepared glass samples are polished and the surfaces are made perfectly plane and smoothened by diamond disc and diamond powder. The glasses produced were, clear and free from defects.

The density, $\mathrm{d}$, of these glasses was determined to an accuracy of 0.001 by the standard Archimedes principle using pure distilled water as the buoyant liquid using the relation

$$
\rho=\rho_{\mathrm{b}} \mathrm{W}_{\mathrm{a}} /\left(\mathrm{W}_{\mathrm{a}}-\mathrm{W}_{\mathrm{b}}\right)
$$

Where $\rho_{\mathrm{b}}$ is the density of the buoyant, $\mathrm{W}_{\mathrm{a}}$ and $\mathrm{W}_{\mathrm{b}}$ are the sample weights in air and the buoyant, respectively.

The molar volume $\left(\mathrm{V}_{\mathrm{m}}\right)$ has been determined as $\mathrm{M} / \rho$ where $\mathrm{m}$ is the molar weight of the glass. The ultrasonic longitudinal $\left(\mathrm{U}_{1}\right)$, shear velocities of the samples were determined using the conventional pulse echo method at room temperature by making use of $4 \mathrm{MHz} \mathrm{X}$-cut and Y-cut transducers. By measuring the elapsed time between the initiation and the receipt of the pulse appearing on the screen of the flaw detector, ultrasonic velocity is then calculated using the relation

$\mathrm{U}=2 * \mathrm{~d} / \mathrm{t}$

where U- velocity of the specimen in $\mathrm{ms}^{-1}$

$$
\mathrm{U}=2 * \mathrm{~d} / \mathrm{t}
$$

d- Thickness of the specimen in $\mathrm{mm}$

t- Transit time.

The measured values of two velocities and the density were used to calculate the various elastic moduli, Debye temperature, Poisson's ratio and micro hardness of the prepared samples.

Table 1: Nominal composition of SMB glass samples

\begin{tabular}{|c|c|c|c|}
\hline \multirow{2}{*}{ Sample } & \multicolumn{3}{|c|}{ Nominal composition (mol \%) } \\
\cline { 2 - 4 } & SrO & $\mathbf{M n O}_{\mathbf{2}}$ & $\mathbf{B}_{2} \mathbf{O}_{\mathbf{3}}$ \\
\hline SMB 1 & 02 & 38 & 60 \\
SMB 2 & 04 & 36 & 60 \\
SMB 3 & 06 & 34 & 60 \\
SMB 4 & 08 & 32 & 60 \\
SMB 5 & 10 & 30 & 60 \\
\hline
\end{tabular}

\subsection{XRD analysis}

\section{Results And Discussion}

Fig 1 shows the XRD pattern of SMB1, SMB5 glasses respectively. It can be seen that there is no continuous or discrete sharp peaks that confirmed the amorphous and homogeneous nature of the all the prepared samples. The absence of long range atomic arrangement is an indication of glassy nature of the samples.

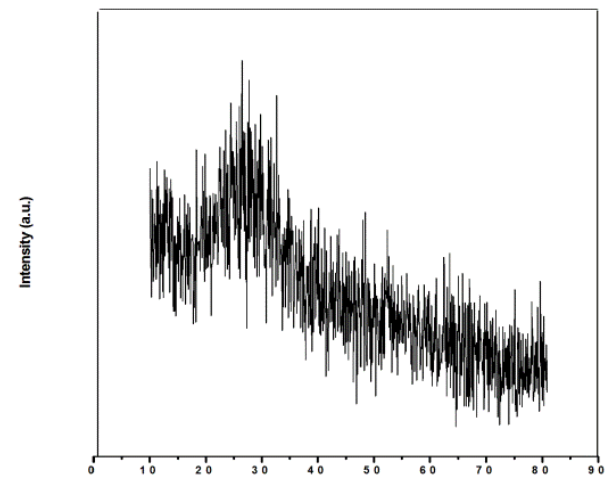

Fig 1. XRD pattern of SMB1 sample

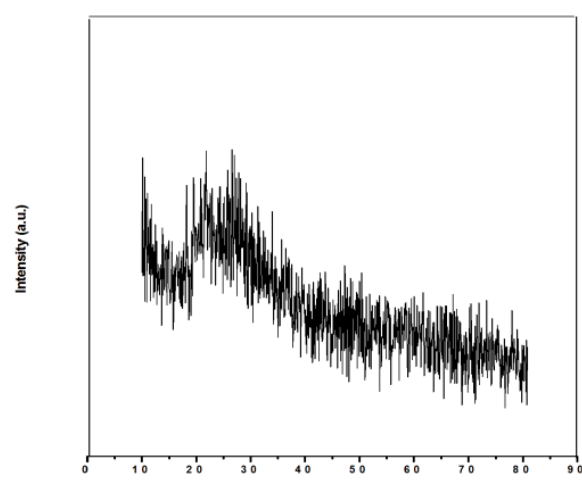

Fig 2. XRD pattern of SMB5 sample

\subsection{Density and molar volume}

The experimental values of density, longitudinal and shear velocities as the function of composition of $\mathrm{MnO}_{2}$ and $\mathrm{SrO}$ are shown in Table 2. The calculated parameters are listed in Table 3. An important property that throws light in understanding the changes occurring in the structure of the glasses influenced by various factors 
such as structural softening, compactness, change in geometrical configuration, coordination number, cross link density and dimension of interstitial spaces of the glass is the density [18]. The heavier molecular mass of SrO predominates the effects of mentioned parameters in determining the density changes of the studied glass. From Table 2, it can be seen that the density increases as the $\mathrm{SrO}$ concentration increases while the molar volume decreases simultaneously. This increase in density may be attributed to the heavier molecular weight of the dopant $\mathrm{SrO}$. Also the addition of $\mathrm{SrO}$ in steps leads to the conversion of large number of $\mathrm{BO}_{3}$ triangles into $\mathrm{BO}_{4}$ tetrahedra which are denser than that of $\mathrm{BO}_{3}$ triangle and hence the increase in density of the developed glass system may arise [19]. Generally the density and molar volume should be opposite to each other and the same is the case in this system also. Here, the molar volume shows a continuous decrease as SrO concentration increases opposite to the density trend. As more $\mathrm{BO}_{4}$ units linked to divalent strontium ions are much denser, occupying less volume, the formation of more $\mathrm{BO}_{4}$ causes the decrease in molar volume. Hence the incorporation of $\mathrm{SrO}$ in the manganese borate glass system contracts the glass network, increases the rigidity of the glasses resulting in a close - packing atomic structure.

Table 2: Values of density $(\rho)$, molar volume $\left(V_{m}\right)$, longitudinal velocity $\left(U_{\ell}\right)$ and shear velocity $\left(U_{s}\right)$ of SMB glass system

\begin{tabular}{|c|c|c|c|c|}
\hline \multirow{2}{*}{ Sample } & \multirow{2}{*}{$\begin{array}{c}\text { Density } \\
\left(\mathbf{\rho} \times \mathbf{1 0}^{\mathbf{3}} \mathbf{k g m}^{-\mathbf{3}}\right)\end{array}$} & $\begin{array}{c}\text { Molar volume } \\
\left.\mathbf{m}^{\mathbf{3}} / \mathbf{m o l}\right)\end{array}$ & $\mathbf{V}_{\mathbf{m}}\left(\times \mathbf{1 0}^{-\mathbf{6}}\right.$ & \multicolumn{2}{|c|}{ Ultrasonic velocity $\left(\mathbf{m s}^{\mathbf{- 1}}\right)$} \\
\cline { 4 - 5 } & 4.4592 & 17.24 & $\begin{array}{c}\text { Longitudinal velocity } \\
\left(\mathbf{U}_{\mathbf{t}}\right)\end{array}$ & $\begin{array}{c}\text { Shear velocity } \\
\left(\mathbf{U}_{\mathbf{s}}\right)\end{array}$ \\
\hline SMB 1 & 4.5016 & 17.15 & 5324 & 2883 \\
SMB 2 & 4.5839 & 16.85 & 5387 & 2931 \\
SMB 3 & 4.6471 & 16.75 & 5429 & 2964 \\
SMB 4 & 4.6983 & 16.64 & 5495 & 3016 \\
SMB 5 & & 5568 & 3075 \\
\hline
\end{tabular}

\subsection{Ultrasonic studies}

The measured values of both longitudinal and shear wave velocities for prepared glass samples are listed in the Table 2. It is observed that both velocities increases as $\mathrm{SrO}$ content increases. The increase in velocities may be attributed to the decrease in molar volume with increase in SrO which implies that there is increase in the connectivity of the glass network structure and hence the increase in elastic moduli. The increase of ultrasonic velocities are the indication of increase in the rigidity, compactness and strength of the glass network [20-24].

The increase in velocities can also be explained by assuming that $\mathrm{Sr}^{2+}$ ions enter interstitially and as a result some modifications in B-O-B and Mn-O-B linkages already existing in the glass network into B-O-Sr bonds may occur creating more number of bridging oxygens which explains that the added strontium modifies the manganese borate glass network structure. Besides, these bridging oxygens created, cause the trigonal borate units to get converted into tetragonal borate units resulting in a decrease in molar volume contracting the glass network. Thus an increase in the rigidity will contribute to the increase in the ultrasonic velocity. This behavior indicates that the replacement of $\mathrm{MnO}_{2}$ by SrO improves the mechanical properties and the strength of the cross links between the chains of borate glasses.

Using the measured ultrasonic velocities and densities, Young's modulus, bulk modulus, micro hardness and Poisson's ratio $\sigma$ can be calculated using the expressions given below and values obtained are listed in the Table 3.

Longitudinal modulus:

$\mathrm{L}=\rho \mathrm{U}_{1}^{2}$

Shear modulus:

$\mathrm{G}=\rho \mathrm{U}_{\mathrm{s}}^{2}$

Bulk modulus:

Poisson's ratio:

$\sigma=\left[\frac{L-2 G}{2(L-G)}\right]$

Young's modulus:

$\mathrm{E}=(1+\sigma) 2 \mathrm{G}$

Acoustic impedance:

$\mathrm{Z}=\mathrm{U}_{\mathrm{l}} \rho$ 
Microhardness:

$$
H=(1-2 \sigma) \frac{E}{6(1+\sigma)}
$$

Debye temperature:

$$
\theta_{\mathrm{D}}=\frac{h}{K}\left(\frac{9 N}{4 \pi V_{m}}\right)^{1 / 3} U_{m}
$$

Where $\mathrm{h}, \mathrm{K}, \mathrm{N}, \mathrm{V}_{\mathrm{m}}$ and $\mathrm{U}_{\mathrm{m}}$ are the Plank's constant $\left(6.626 \times 10^{-34} \mathrm{JS}\right)$, the Boltzmann's constant $\left(1.38 \times 10^{-23}\right.$ $\left.\mathrm{JK}^{-1}\right)$, Avogadro's number $\left(6.023 \times 10^{23} \mathrm{~mol}^{-1}\right)$, mean sound velocity of the sample respectively where

$$
\mathrm{U}_{\mathrm{m}}=\left[\frac{1}{3}\left(\frac{2}{U_{s}^{3}}+\frac{1}{U_{\ell}^{3}}\right)\right]^{-1 / 3}
$$

Thermal expansion coefficient $\left(\mathbf{a}_{\mathrm{p}}\right)$ :

$$
\alpha_{\mathrm{p}}=23.2\left(\mathrm{U}_{1}-0.57457\right)
$$

Table 3. Values of longitudinal (L), shear (G), bulk (K) and Young's modulus $(E)$ and Poisson's ratio $(\sigma)$ of SMB glass system

\begin{tabular}{|c|c|c|c|c|c|}
\hline Sample & $\begin{array}{c}\text { Longitudinal } \\
\text { modulus } \\
\text { L (GPa) }\end{array}$ & $\begin{array}{c}\text { Shear modulus } \\
\text { G }(\mathbf{G P a})\end{array}$ & $\begin{array}{c}\text { Bulk } \\
\text { modulus } \\
\text { K (GPa) }\end{array}$ & $\begin{array}{c}\text { Young's modulus } \\
\mathbf{E}(\mathbf{G P a})\end{array}$ & $\begin{array}{c}\text { Poisson's ratio } \\
(\boldsymbol{\sigma})\end{array}$ \\
\hline SMB 1 & 126.39 & 37.06 & 76.98 & 95.81 & 0.292 \\
SMB 2 & 130.63 & 38.67 & 79.07 & 99.75 & 0.289 \\
SMB 3 & 135.11 & 40.27 & 81.41 & 103.71 & 0.287 \\
SMB 4 & 140.32 & 42.27 & 83.96 & 108.59 & 0.284 \\
SMB 5 & 145.66 & 44.43 & 86.43 & 113.78 & 0.280 \\
\hline
\end{tabular}

Table 4. Values of acoustic impedance $(Z)$, microhardness $(H)$,Debye temperature $\left(\theta_{D}\right)$, and thermal expansion co - efficient $\left(\alpha_{\mathrm{p}}\right)$ of SMB glass system

\begin{tabular}{|c|c|c|c|c|}
\hline Sample & $\begin{array}{c}\text { Acoustic impedance } \\
\mathbf{Z}\left(\mathbf{1 0}^{\mathbf{7}} \mathbf{~ k g m ~}^{-2} \mathbf{~}^{-1}\right)\end{array}$ & $\begin{array}{c}\text { Micro } \\
\text { Hardness H (GPa) }\end{array}$ & $\begin{array}{c}\text { Debye } \\
\text { temperature } \boldsymbol{\theta}_{\mathbf{D}}(\mathbf{K})\end{array}$ & $\begin{array}{c}\text { Thermal expansion } \\
{\text { co-efficient } \boldsymbol{\alpha}_{\mathbf{p}}}_{\left(\mathbf{1 0}^{\mathbf{3}} \mathbf{m s}^{-\mathbf{1}}\right)}\end{array}$ \\
\hline SMB 1 & 2.374 & 1.54 & 451.66 & 123.503 \\
SMB 2 & 2.425 & 1.59 & 459.79 & 124.965 \\
SMB 3 & 2.489 & 1.62 & 467.60 & 125.939 \\
SMB 4 & 2.554 & 1.68 & 476.49 & 127.470 \\
SMB 5 & 2.616 & 1.75 & 486.66 & 129.164 \\
\hline
\end{tabular}

Elastic moduli are sensitive to any changes in the nature of chemical bonds, strength as well as the cross link density of the material characterizing the glass structure. In this system, the values of all elastic moduli increase with increase in velocity and density values with the increase in concentration of SrO. It is well known that the rigidity is related to the moduli, and hence increase in elastic moduli explains the increase in the strength of the glass network. The value of longitudinal modulus increases from 126.39 to $145.66 \mathrm{GPa}$ and shear varies from 37.06 to $44.43 \mathrm{GPa}$ while the bulk modulus increases from 76.98 - $86.43 \mathrm{GPa}$ and Young's modulus from 95.81 to $113.78 \mathrm{GPa}$. This behavior is due to increase in network dimensionality and connectivity. The rate of change of elastic moduli is more pronounced in $\mathrm{L}$ and least in $\mathrm{G}$. 
The observed change in the elastic properties of the studied glasses can be interpreted by taking into account the relation between bulk modulus and molar volume [25]. Here bulk modulus varies from 76.98 to $86.43 \mathrm{GPa}$ which shows that the type of bonding is also important in determining the composition dependence of bulk modulus in these glasses. Such behavior of bulk modulus - volume relationship was observed in some other types of glasses. High field strength cation of the modifier plays an important role in increasing the packing density as those cations polarize their environment strongly and enhance the ion-dipole interaction leading to local contraction of the network around such a cation together with the effects of increasing the bulk modulus. In general, elastic moduli increase while the density or ultrasonic velocity increases [26]. This indicates that there is increase in the formation of bridging oxygens, hence transforming borate triangular units in to denser, stronger tetrahedras which cause the more compact structure.

Poisson's ratio is the ratio of lateral and longitudinal strain when tensile force is applied. Normally the increase in the rigidity of the glasses contributes an increase in velocity and caused an increase in the Poisson's ratio. According to Rao, Poisson's ratio varies as a function of dimensionality of the structure and cross link density [27]. In this study, as the concentration of SrO increases, Poisson's ratio increases. Cross link density of the glass decides the Poisson's ratio. If the cross-link density of the structure is high, then Poisson's ratio value falls in the range of 0.1- 0.2 while those with low value have Poisson's ratio in between 0.3-0.5. In the present glass system, the value lies between $0.2-0.3$ which indicates that the cross-link density is high. The increase in Poisson's ratio is due to the increase in the average cross-link density of the glass as proposed by Higacy and Bridge [28]. This is also due to branching of network linkages and formation of smaller structural units in the glass samples. The observed decrease in Poisson's ratio due to the progressive addition of SrO explains the introduction of covalent bonds $\mathrm{B}-\mathrm{O}-\mathrm{Sr}$ and more bridging oxygens leading to more $\mathrm{BO}_{4}$ units that formed the more rigid glass network.

Debye temperature is one of the important parameters which helps to determine the elastic moduli and lattice vibrations. The entire lattice vibrational modes get excited at this particular temperature which depends directly on the mean ultrasonic wave velocity and varies as the velocities vary. In our system as the velocities show an increasing trend, hence the Debye temperature is. The increase in Debye temperature and thermal expansion coefficient indicate the increase in stability of the glass system resulting due to the subsequent addition of $\mathrm{SrO}$ indicating the tight packing of glass network structure and B-O-Sr linkage formation.

Microhardness is the resistance offered by the material to permanent indentation, a property to study the characterization of solids. It also increases like the increase in elastic moduli shown confirming the compactness and stiffness of the glass system arising because of the increase in concentration of added $\mathrm{SrO}$ creating sufficient number of bridging oxygens thereby reducing the molar volume, increasing the density and hence the compactness and rigidity.

\section{Conclusion}

Elastic properties of the manganese borate glass system are explored to study the impact of SrO. The increase in the values of density, ultrasonic velocities and hence the various elastic moduli with the increase in concentration of $\mathrm{SrO}$ implies the conversion of three coordinated boron into four coordinated borons thereby increasing the rigidity and hence the compactness of glass structure. The similar trend is observed in the Poisson's ratio, Debye temperature and micro hardness due to $\mathrm{SrO}$ doping. Therefore it is concluded that the addition of $\mathrm{SrO}$ improves the strength and stability of manganese borate glass system.

\section{References}

[1]. W.D Kingrey, Introduction to ceramics (Marcell Dekkar Inc.,) 1976, 102.

[2]. A.Terczynska-Madej, K.cholewa-Kowalska,M.laczka. The effect of silicate network modifiers on colour and electron spectra of transition metal ions, Opt.Mater . 32(11), 2010, 1456-1462

[3]. P.Venkat Reddy, C.Laxmi Kanth,V.Prashanth Kumar,N.veeraiah, P.Kistaiah. Optical and thermoluminescence properties of $\mathrm{R}_{2} \mathrm{O}-$ RF- $\mathrm{B}_{2} \mathrm{O}_{3}$ glass systems doped with MnO, J.Non-Cryst.Solids . 351, 2005, 3752 -3759.

[4]. A.K.Arof, S.Radhakrishna. Raman spectroscopic studies of silver borotungstate Battery Materials, Mater.Sci.Eng. B. 38 (1-2), 1996,76-79.

[5]. Souto, S., M. Massot, M. Balkanski and D. Royer. Density and ultrasonic velocities in fast ionic conducting borate glasses, Mater. Sci. Eng.B. 64, 1999, 33-38

[6]. E.Culiea, Tania Ristolu, I.Bratu. Magnetic and structural behavior of some borate glasses containing holomium ions, Mater.Sci. Eng B. 57 ( 3), 1999, 259-261.

[7]. E.I.Kamitsos, G.D.chryssikos. Borate glass structure by Raman and infrared spectroscopies. J.mol.struct. $247,1991,1$.

[8]. A.Ivankov, J.seekamp, W.Bauhofer,Optical properties of zinc borate glasses, Mater.lett. 49 (3 - 4), 2001, 209 - 213.

[9]. S.Sanghi, S.Rani, A.Agarwal, V.Bhatnagar. Influence of $\mathrm{Nb}_{2} \mathrm{O}_{5}$ on the structure, optical and electrical properties of alkaline borate glasses, Mater.Chem.Phys. 120, 2010, 381-386.

[10]. G.E.Falaky, O.W.Guirguis. Effect of zinc on the physical properties of borate glasses, J. Non .Cryst. Solids. 358(15) 2012 : 17461752 .

[11]. B.Sumalatha, I.Omkaram, T.Rajavardhana Rao, Ch. Linga Raju. The structural, optical and magnetic parameter of manganese doped strontium zinc borate glasses, Physica B. 411,2013, 99-105. 
[12]. G. Venkateswara Rao, N.veeraiah, P.Yadhagiri Reddy., Luminescence quenching by manganese ions in $\mathrm{MO}_{-} \mathrm{CaF}_{2}-\mathrm{B}_{2} \mathrm{O}_{3}$ glasses, Opt.materials. 22(4), 2003, 295-302.

[13]. K. Annapoorani, N.Suria Murthy, T.R. Ravindran, K.Marimuthu. Influence of $\mathrm{Er}^{3+}$ ion concentration on spectroscopic properties and luminescence behavior in $\mathrm{Er}^{3+}$ doped Strontium telluroborate glasses, J.Lumin. 171, 2016, 19-26.

[14]. R.S.Kaundal, Sandheep Kaur, Narveer Singh, K.J.Singh. Investigation of structural properties of lead strontium borate glasses for gamma-ray shielding applications, J.Phy.Chem. Solids. 71(9), 2010,1191-1195.

[15]. Kathleen Macdonald, Margaret A. Hanson, Daniel Boyd. Modulation of strontium release from a tertiary borate glass through substitution of alkali for alkali earth oxide, J. Non .Cryst. Solids. 443, 2016, 184-191.

[16]. M.A.Marzouk, F.H. Elbatal, W.H.Eisa, N.A.Ghoneim. Comparative spectral and shielding studies of binary borate glasses with the heavy metal oxides $\mathrm{SrO}, \mathrm{CdO}, \mathrm{BaO}, \mathrm{PbO}$ or $\mathrm{Bi}_{2} \mathrm{O}_{3}$ before and after gamma irradiation, J. Non .Cryst. Solids. $38,2014,155-160$.

[17]. M.S. Gaffer, F.H. El batal, M. El Gazery, S.A. Mansour .Effect of Doping by Different Transition Metals on the Acoustical Properties of Alkali Borate Glasses, Acta Physica Polonica. 115, 2009, 3.

[18]. Yasser B. Sadeek. Ultrasonic study and physical properties of some borate glasses, Mat. Chem. Phy . 83(2) , 2004, 222-228.

[19]. S.Rada, P.Pascuta,, M.culea, V. Maties, M.Rada,,M.Barlea,E.Culea. The local structure of europium- lead glass ceramics, J.Mol.Struct. $924-926,2009,89-92$.

[20]. A. Abd El-Moneim. Interpretation of elastic Mater.Chem.Phys. Properties and structure of $\mathrm{TiO}_{2}-\mathrm{CaO}^{-} \mathrm{Al}_{2} \mathrm{O}_{3}-\mathrm{B}_{2} \mathrm{O}_{3}$ glasses, Phys.Chem. Glasses. 45, 2004, 15-20.

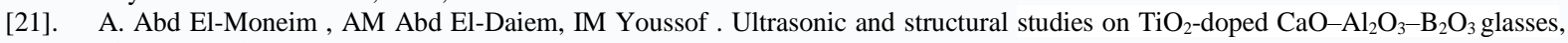
Phys.Stat.Sol.a. 2003; 192-201.

[22]. A. Abd El-Moneim . Quantitative analysis of ultrasonic attenuation in $\mathrm{TiO}_{2}$-doped $\mathrm{CaO}-\mathrm{Al}_{2} \mathrm{O}_{3}-\mathrm{B}_{2} \mathrm{O}_{3}$ glasses, $\mathrm{Mater}$ Chem.Phys. 98 , 2006, 261-266.

[23]. K.J. Singh, S.S Bhatti. Elastic Moduli of Ferric Oxide Doped Zinc Oxide Borate Glasses, Acoustica, 81(3), 1995 , $285-287$.

[24]. SP.Yawale, SV Pakede, CS Adgaonkar. A New Type of Behaviour in Physical and Ultrasonic Properties of Bi2 $\mathrm{O}_{3}-\mathrm{B}_{2} \mathrm{O}_{3} \mathrm{Glasses}$ Acoustica 1995; 81:184-186.

[25]. V. Rajendren, N.Palanivelu, R.Chaudhuri, K. Goswami. Characterization of semiconducting $\mathrm{V}_{2} \mathrm{O}_{5}-\mathrm{Bi}_{2} \mathrm{O}_{3}-\mathrm{TeO}_{2}$ glasses through ultrasonic measurements. J. Non .Cryst. Solids 2003: 320 (1) : 195-209.

[26]. K.Rao, Structural Chemistry of Glasses. Elsevier, North Holland 2002.

[27]. A.A. Higacy, B.Bridge. Elastic constants of the vitreous system $\mathrm{Co}_{3} \mathrm{O}_{4}-\mathrm{P}_{2} \mathrm{O}_{5}$. J. Non .Cryst. Solids $1985 ; 72(1)$ : 81-108.

IOSR Journal of Applied Physics (IOSR-JAP) is UGC approved Journal with S1. No. 5010, Journal no. 49054.

P. Vasantharani. "Structural and Elastic Studies of Strontium Doped Manganese Borate Glasses." IOSR Journal of Applied Physics (IOSR-JAP) 9.4 (2017): 44-49. 